such a trial is problematic because it doesn't involve a drug that pharma can profit from.

Then there's the yuck factor, she adds. "No hospital would support doing this study on their grounds except for ours."

C. difficile is a bacteria that is believed to cause diarrhea and such intestinal diseases as colitis when normal bacteria in the gut are eradicated by antibiotics. $C$. difficile spores may be ingested by patients in hospitals, nursing homes and health care settings. Severe infections are typically treated by vancomycin or metronidazole.

But Hota says the etiology of $C$. difficile infections is unclear and the study hopes to pinpoint the causes. "We think it's more than just the bacteria."

A review of 100 Scandinavian cases found that fecal bacteriotherapy cured
89\% of patients (Anaerobe. 2009;15: 285-90). Dr. Johan Bakken, the review author and a gastroenterologist in Duluth, Minnesota, says the risk of transmitting a contagious agent through fecal bacteriotherapy is merely "theoretical."

Bakken says there hasn't been a single reported case of a transmitted infection agent. He also estimates that more than 500 unpublished fecal transplants have occurred, most of those without donor screening because of its high cost. In most sites where a fecal transplants are undertaken, donors are a "bed or table contact" of the infected individual, to minimize the risk of disease transmission, Bakken adds.

Not so at St. Joseph's Hospital in Hamilton, Ontario, where doctors have relied on a small pool of screened donors for material used to undertake more than 50 fecal transplants over the past 18 months. "Organizing and mobilizing families for transplants was challenging," says Dr. David Higgins, the hospital's chief of staff. "It felt unfair to offer it to some people and not others."

Higgins says $90 \%$ of the patients treated have been effectively cured and there hasn't been any known transmission of infectious diseases. "We're getting institutions contacting us from across the country to see if we can deal with other patients."

As for the yuck factor, Bakken notes that patients aren't squeamish. "Those that voice objection to the therapy are not the patients themselves because they are at last straw." - Wendy Glauser, Toronto, Ont.

CMAJ 2011. DOI:10.1503/cmaj.109-3806

\title{
Patient safety database goes online
}

A Canadian-developed, Webbased patient safety alert database has been launched to collate information about harmful incidents from around the world in hopes it will spur reforms to prevent similar incidents in the future.

The publicly accessible site, Global Patient Safety Alerts, will contain summaries and links to more than 900 recent patient safety advisories, alerts and recommendations on incidents in which a patient was harmed, or had the potential to be harmed, from some 22 international, national and regional health authorities and organizations worldwide (www.globalpatientsafety alerts.com).

The Canadian Patient Safety Institute (CPSI) developed the site to give health care providers and policy-makers an opportunity to become aware of adverse events, identify similarities and patterns in sources of risk, share solutions and ultimately, prevent similar ones from occurring in the future.

"It's transparency gone wild," says institute CEO Hugh MacLeod. "The reality is we're working in very com-

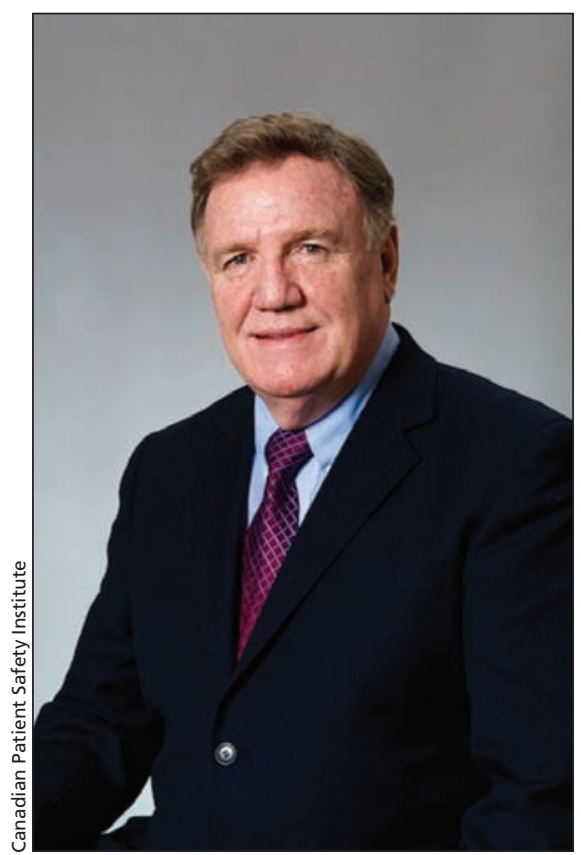

"It's transparency gone wild," says Canadian Patient Safety Institute CEO Hugh MacLeod.

plex, fast-moving systems. We have new drugs, new technologies, but also new demands and expectations from the public, and mistakes happen. Now, however, we can begin to share, ana- lyze and learn from those mistakes on a broader scale."

Historically, when an incident occurred in one jurisdiction, other regions were not made aware of the mistake, and did not benefit from the lessons learned, because no global system existed to gather and share the information, says Paula Beard, CPSI director of operations, citing recent oxygen tube mix-ups as an example. "Incidents were happening on a oneoff basis in hospitals across Canada. What we've now found out through our system is that they were also happening around the world and a number of solutions had been implemented, but there wasn't any coordination between the organizations that were trying to solve that problem."

The website aggregates data from groups that produce $80 \%$ to $85 \%$ of global patient safety information, including the health authorities and incident reporting systems of the European Union, United Kingdom, Australia and a number of American states. It also collates patient safety alerts from organizations such as the 
Institute for Safe Medication Practices Canada and the UK-based National Patient Safety Agency.

CPSI creates summaries of all the information it gathers to allow "timepressed" users to readily assess whether it's something they "want to spend more time on, or is this a little off point and I want to keep looking," says Beard. The summaries, which are reviewed for clinical accuracy, are also translated into World Health Organization (WHO)-approved nomenclature so that users can easily "compare apples with apples."

Recommendations and proposed solutions to patient safety problems are posted in their own section on the database for ease of access, she adds.

The ultimate goal is to create a "Google-like" search engine that can be used in both a "proactive and reactive" way, Beard says. "On one hand, policy- and decision-makers can look at what others have tried and perhaps even connect with those jurisdictions before embarking on what could be costly changes to the system. On the other, when a patient is harmed, the individual responsible for reviewing that incident can come here first to see how they can improve on previous efforts."

During the official launch of the site, WHO chair of patient safety Liam Donaldson said the database was the equivalent of an orange wire that's found disconnected during a preflight inspection of a jumbo jet. The wire is subsequently repaired and the incident is reported to a network of engineers who then check all jets of the same make to ensure the fault is not systemic.

"We're not there yet with patient safety," MacLeod says. "But this is much closer to that vision of what the future of incident reporting might look like."

CPSI also expects to soon debut an online portal for patient safety tools and resources, of which the Global Patient Safety Alerts site will be one. — Lauren Vogel, CMAJ

CMAJ 2011. DOI:10.1503/cmaj.109-3818

\section{More news at www.cmaj.ca}

Sexuality of the disabled often overlooked: The sexuality of people with disabilities, many of whom require varying degrees of assistance to lead fulfilling sex lives, continues to be overlooked, avoided or even dismissed as a component of holistic care because of a longstanding stigma that shrouds disability and sex. A dearth of resources, training and infrastructure to guide caregivers and patients in addressing sexual needs contributes to the problem. - William Burr, Ottawa, Ont.

Public health advocates push for safer sex in pornographic film industry: Sex sells, but can it educate? That's the crux of debate over a transformation within the pornographic film industry that public health advocates argue is required to promote safer sex in the general population through more extensive use of condoms. - Lauren Vogel, CMAJ

No-fault compensation program overdue, experts say: Canada and Russia are the only G8 nations without national no-fault compensations programs for people injured from vaccines, and according to Canadian vaccine experts, it is high time Canada make its exit from that short but inglorious list. — Roger Collier, CMAJ

Grief therapy for those left behind: The provision of grief therapy for the families of dying patients is seen by some as an integral component of palliative care. - Roger Collier, CMAJ

Providing hospice in the womb: The growth of prenatal diagnostic technologies has resulted in increased demand for perinatal palliative care to ensure that terminally ill babies are comfortable during their short lives and that families receive psychological support. — Roger Collier, CMAJ

Mental health still a minefield at the front: Treating mental health problems of Canadian soldiers in Afghanistan requires finding a balance between protecting the soldier from further trauma and returning him to work as soon as possible, a military expert says. — Lauren Vogel, CMAJ

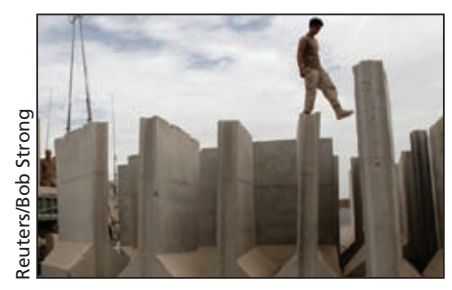

United States reviews safety of electroconvulsive therapy: The United States government is taking a closer look at electroshock treatment, long a controversial treatment for severe depression and other psychiatric disorders, to determine if the therapy should be subject to more stringent oversight or reclassified as lower-risk. - Nancy Benac, Washington, DC

\section{Dispatch from the medical front}

Death and suffering in the land of Genghis Khan: In Mongolia, a dzud, or extreme winter storm, can impede access to health care for weeks and cause other hardships, particularly for nomadic herders. - Lauralee Morris, MD, Ulaanbataar, Mongolia

CMAJ 2011. DOI:10.1503/cmaj.109-3823 